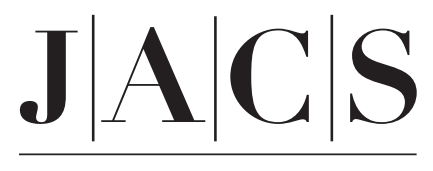

A R T I C L E S

Published on Web 10/05/2007

\title{
Meta Conjugation Effect on the Torsional Motion of Aminostilbenes in the Photoinduced Intramolecular Charge-Transfer State
}

\author{
Jye-Shane Yang, ${ }^{*}{ }^{\dagger}$ Kang-Ling Liau, ${ }^{\ddagger}$ Chun-Yi Li ${ }^{\dagger}$ and Mon-Yao Chen ${ }^{\ddagger}$ \\ Department of Chemistry, National Taiwan University, Taipei, Taiwan 10617 and Department of \\ Chemistry, National Central University, Chungli, Taiwan 32054
}

Received June 6, 2007; E-mail: jsyang@ntu.edu.tw

\begin{abstract}
The photochemical behavior of a series of trans-3-(N-arylamino)stilbenes ( $\mathbf{m} \mathbf{1}$, aryl = 4-substituted phenyl with a substituent of cyano $(\mathbf{C N})$, hydrogen $(\mathbf{H})$, methyl $(\mathbf{M e})$, or methoxy $(\mathbf{O M})$ ) in both nonpolar and polar solvents is reported and compared to that of the corresponding para isomers $(\mathbf{p} 1 \mathbf{C N}, \mathbf{p} \mathbf{1 H}, \mathbf{p} 1 \mathbf{M e}$, and $\mathbf{p 1 O M}$ ). The distinct propensity of torsional motion toward a low-lying twisted intramolecular chargetransfer (TICT) state from the planar ICT (PICT) precursor between the meta and para isomers of $1 \mathrm{CN}$ and $1 \mathrm{Me}$ reveals the intriguing meta conjugation effect and the importance of the reaction kinetics. Whereas the poor charge-redistribution (delocalization) ability through the meta-phenylene bridge accounts for the unfavorable TICT-forming process for $\mathbf{m} 1 \mathbf{C N}$, it is such a property that slows down the decay processes of fluorescence and photoisomerization for $\mathbf{m} 1 \mathrm{Me}$, facilitating the competition of the single-bond torsional reaction. In contrast, the quinoidal character for $\mathbf{p} 1 \mathrm{Me}$ in the PICT state kinetically favors both fluorescence and photoisomerization but disfavors the single-bond torsion. The resulting concept of thermodynamically allowed but kinetically inhibited TICT formation could also apply to understanding the other D-A systems, including trans-4-cyano-4'-( N,N-dimethylamino)stilbene (DCS) and 3-( N,N-dimethylamino)benzonitrile (3DMABN).
\end{abstract}

\section{Introduction}

The electronic properties such as photoluminescence, energy migration, electron transfer, conductivity, and nonlinear optics for a $\pi$-conjugated system strongly depend on the degree of electronic coupling (delocalization) between the subunits. ${ }^{1-8}$ It is well known that electronic coupling through a meta-phenylene

National Taiwan University.

$\doteqdot$ National Central University.

(1) (a) Karabunarliev, S.; Baumgarten, M.; Tyutyulkov, N.; Müllen, K. J. Phys. Chem. 1994, 98, 11892-11901. (b) Tammer, M.; Horsburgh, L.; Monkman, A. P.; Brown, W.; Burrows, H. D. Adv. Funct. Mater. 2002, 12, 447-454 (c) Chu, Q.; Pang, Y.; Ding, L.; Karasz, F. E. Macromolecules 2002, 35 , 7569-7574. (d) Oliva, M. M.; Casado, J.; Hennrich, G.; Navarrete, J. T. L. J. Phys. Chem. B 2006, 110, 19198-19206.

(2) (a) Hong, S. Y.; Kim, D. Y.; Kim, C. Y.; Hoffmann, R. Macromolecules 2001, 34, 6474-6481. (b) Pogantsch, A.; Mahler, A. K.; Hayn, G.; Saf, R.; Stelzer, F.; List, E. J. W.; Brédas, J.-L.; Zojer, E. Chem. Phys. 2004 297, 143-151. (c) Yang, J.-S.; Lee, Y.-R.; Yan, J.-L.; Lu, M.-C. Org. Lett. 2006, 8, 5813-5816.

(3) (a) Díez-Barra, E.; García-Martínez, J. C.; Merino, S.; del Rey, R.; Rodríguez-López, J.; Sánchez-Verdú, P.; Tejeda, J. J. Org. Chem. 2001, 66, 5664-5670. (b) Gaab, K. M.; Thompson, A. L.; Xu, J.; Martinez, T. J.; Bardeen, C. J. J. Am. Chem. Soc. 2003, 125, 9288-9289. (c) Thompson, A. L.; Gaab, K. M.; Xu, J.; Bardeen, C. J.; Martinez, T. J. J. Phys. Chem. A 2004, 108, 671-682. (d) Ranasinghe, M. I.; Hager, M. W.; Gorman, C. B.; Goodson, T., III J. Phys. Chem. B 2004, 108, 8543-8549.

(4) Song, C.; Swager, T. M. Macromolecules 2005, 38, 4569-4576.

(5) (a) Yamaguchi, Y.; Kobayashi, S.; Wakamiya, T.; Matsubara, Y.; Yoshida, Z. Angew. Chem., Int. Ed. 2005, 44, 7040-7044. (b) Priego, E. M.; Sánchez, L.; Herranz, M. A.; Martín, N.; Viruela, R.; Ortí, E. Org. Biomol. Chem. 2007, 5, 1201-1209.

(6) (a) Bangal, P. R.; Lam, D. M. K.; Peteanu, L. A.; Van der Auweraer, M. J. Phys. Chem. B 2004, 108, 16834-16840. (b)Yamaguchi, Y.; Ochi, T.; Miyamura, S.; Tanaka, T.; Kobayashi, S.; Wakamiya, T.; Matsubara, Y.; Yoshida, Z. J. Am. Chem. Soc. 2006, 128, 4504-4505.

(7) Thompson, A. L.; Ahn, T.-S.; Thomas, K. R. J.; Thayumanavan, S.; Martinez, T. J.; Bardeen, C. J. J. Am. Chem. Soc. 2005, 127, 16348-16349.

10.1021/ja0741022 CCC: $\$ 37.00$ @ 2007 American Chemical Society
$(m-\mathrm{Ph})$ bridge is inherently weaker than through a paraphenylene $(p-\mathrm{Ph})$ one. ${ }^{1,2}$ However, recent studies have shown that their difference becomes smaller on going from the ground to the excited state, ${ }^{3}$ and the meta conjugation effect could be further enhanced by structural modifications on the Ph bridge (e.g., replaced by pyridyl or phenol groups $)^{4,5}$ or the subunits (e.g., presence of electron-donating amino or alkoxy groups). ${ }^{6}$ Such a state- and structure-dependent meta conjugation effect could be a merit for designing new organic materials. Indeed, it has recently been revealed that meta-bridged electron donoracceptor (D-A) systems are potential candidates as highefficiency solar-cell sensitizers because upon electronic excitation the meta bridge allows efficient intramolecular charge transfer (ICT) for the desired charge-separation but not for the unwanted charge-recombination processes. ${ }^{7}$

Another crucial factor that determines the degree of electronic coupling in $\pi$-conjugated systems is the conformation: namely, the more planar the molecular structure, the stronger the coupling. While electronic excitation generally planarizes the system and thus increases the charge-delocalization (mesomeric) interactions, ${ }^{9}$ discrepancies have been found for some D-A systems, which undergo torsional motion about the $\mathrm{D}-\mathrm{A}$ bond and lead to a charge-separated twisted ICT (TICT) state (Figure

(8) (a) Peng, Z.; Pan, Y.; Xu, B.; Zhang, J. J. Am. Chem. Soc. 2000, 122, 6619-6623. (b) Melinger, J. S.; Pan, Y.; Kleiman, V. D.; Peng, Z.; Davis, B. L.; McMorrow, D.; Lu, M. J. Am. Chem. Soc. 2002, 124, 12002-12012. (c) Pan, Y.; Lu, M.; Peng, Z.; Melinger, J. S. J. Org. Chem. 2003, 68 6952-6958. (d) Tomonari, M.; Ookubo, N. Chem. Phys. Lett. 2003, 376, $504-514$

J. AM. CHEM. SOC. 2007, 129, 13183-13192 - 13183 


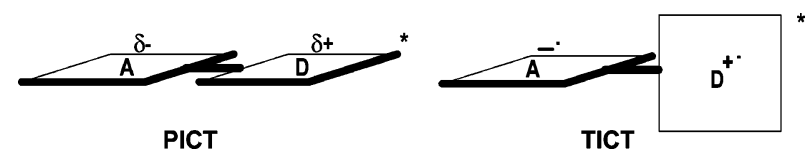

Figure 1. Schematic drawing of geometries and electronic character for the PICT and TICT states of electron donor (D)-acceptor (A) conjugated systems.

1). ${ }^{10,11}$ The driving force for the TICT state formation is to increase the dipole moment and thus gain better solvation in polar solvents. The TICT concept originated from the interpretation of the dual fluorescence behavior of $4-(N, N$-dimethylamino)benzonitrile (DMABN) in polar solvents. ${ }^{12}$ The proposed TICT state is a successor of the so-called locally excited (LE) state through the twisting of the $\mathrm{C}_{\mathrm{ph}}-\mathrm{N}$ bond. Because of the forbidden nature in optical transition for the charge-recombination process, the TICT state is characterized with low fluorescence quantum efficiency. However, such an argument has been challenged by several other alternative models, and the most important one is the planar ICT (PICT) state. ${ }^{13,14}$ Recent progress on this issue has revealed that dual fluorescence could result from the LE-PICT or the PICT-TICT as well as the LETICT states, depending on the molecular structures. ${ }^{15}$ TICTbased dual fluorescent systems have been applied in the design of ratiometric fluorescent chemosensors. ${ }^{16}$ In addition, the TICT concept has inspired the design of ground-state twisted zwitterionic D-A systems of ultralarge hyperpolarizability. ${ }^{17}$

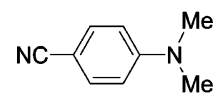

DMABN

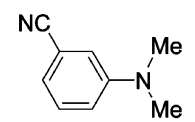

3DMABN

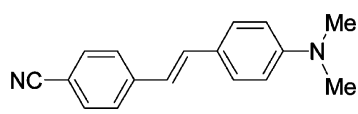

DCS
Despite the numerous investigations of the ICT behavior of D-A systems, to predict whether a TICT state is formed simply based on the molecular structure remains to be a challenging task. For example, the meta isomer of DMABN (i.e., 3DMABN)

(9) For examples, see: (a) Sluch, M. I.; Godt, A.; Bunz, U. H. F.; Berg, M. A J. Am. Chem. Soc. 2001, 123, 6447-6448. (b) Yang, J.-S.; Yan, J.-L.; Hwang, C.-Y.; Chiou, S.-Y.; Liau, K.-L.; Tsai, H.-S. G.; Lee, G.-Hs.; Peng, S.-M. J. Am. Chem. Soc. 2006, 128, 14109-14119.

(10) (a) Rettig, W. Angew. Chem., Int. Ed. Engl. 1986, 25, 971-988. (b) Rettig, W.; Maus, M. Conformational Analysis of Molecules in Excited States Waluk, J., Ed.; Wiley-VCH: New York, 2000; Chapter 1, pp 1-55.

(11) Grabowski, Z. R.; Rotkiewicz, K. Chem. Rev. 2003, 103, 3899-4031.

(12) (a) Lippert, E.; Lüder, W.; Moll, F.; Nägle, W.; Boos, H.; Prigge, H.; Seibold-Blankenstein, I. Angew. Chem. 1961, 73, 695-706. (b) Lippert, E.; Lüder, W.; Boos, H. In Advances in Molecular Spectroscopy; Mangini, A., Ed.; Pergamon Press: Oxford, 1962, pp 443-457.

(13) (a) von der Haar, T.; Hebecker, A.; Il'ichev, Y. V.; Jiang, Y.-B.; Kühnle, W.; Zachariasse, K. A. Recl. Trav. Chim. Pays-Bas 1995, 114, 430-442. (b) Zachariasse, K. A.; Grobys, M.; von der Haar, T.; Hebecker, A.; Il'ichev, Y. V.; Jiang, Y.-B.; Morawski, O.; Kühnle, W. J. Photochem. Photobiol. A: Chem. 1996, 102, 59-70. (c) Zachariasse, K. A.; Grobys, M.; von der Haar, T.; Hebecker, A.; Il'ichev, Y. V.; Morawski, O.; Rückert, I.; Kühnle, W. J. Photochem. Photobiol. A: Chem. 1997, 105, 373-383. (d) Il'ichev, Y. V.; Kühnle, W.; Zachariasse, K. A. J. Phys. Chem. 1998, 102, 56705680. (e) Demeter, A.; Zachariasse, K. A. Chem. Phys. Lett. 2003, 380 699-703. (f) Zachariasse, K. A.; Druzhinin, S. I.; Bosch, W.; Machinek, R. J. Am. Chem. Soc. 2004, 126, 1705-1715. (g) Techert, S.; Zachariasse, K. A. J. Am. Chem. Soc. 2004, 126, 5593-5600.

(14) (a) Zachariasse, K.; van der Haar, T.; Hebecker, A.; Leinhos, U.; Kühnle, W. Pure Appl. Chem. 1993, 65, 1745-1750. (b) Zachariasse, K. A. Chem Phys. Lett. 2000, 320, 8-13.

(15) Cogan, S.; Zilberg, S.; Haas, Y. J. Am. Chem. Soc. 2006, 128, 33353345 .

(16) (a) Létard, J.-F.; Delmond, S.; Lapouyade, R.; Braun, D.; Rettig, W.; Kreissler, M. Recl. Trav. Chim. Pays-Bas 1995, 114, 517-527. (b) Collins, G. E.; Choi, L.-S.; Callahan, J. H. J. Am. Chem. Soc. 1998, 120, 14741478. (c) Aoki, S.; Kagata, D.; Shiro, M.; Takeda, K.; Kimura, E. J. Am Chem. Soc. 2004, 126, 13377-13390. (d) Liu, B.; Chen, J.; Yang, G.; Li, Y. Res. Chem. Intermed. 2004, 30, 345-353. (e) Yang, J.-S.; Hwang, C.Y.; Chen, M.-Y. Tetrahedron Lett. 2007, 48, 3097-3102. displays an anti-TICT behavior (e.g., nondual fluorescence and large fluorescence quantum yields), ${ }^{14,18}$ although its TICT state was expected to be lower in energy than the LE state. ${ }^{14,19}$ Likewise, the $\pi$-elongated DMABN analog trans-4-cyano-4'( $N, N$-dimethylamino)stilbene (DCS) was computationally predicted to possess a low-lying TICT state, ${ }^{20}$ but many experimental studies have shown it to be a TICT-free species. ${ }^{21-23}$ While such discrepancies have been employed to argue against the validity of the TICT model, ${ }^{14,21,22}$ an alternative explanation is the unfavorable reaction kinetics. In other words, a low-lying TICT state (i.e., thermodynamically favorable) might not guarantee its formation unless the process of the torsional motion is also sufficiently fast to compete with the other decay channels. However, addressing the TICT kinetics for a D-A system is by no means straightforward. This is evidenced by the fact that even for the prototype DMABN molecule the reaction mechanism is still under discussion. ${ }^{11,24,25}$ For example, a torsional barrier is present in the conventional adiabatic precursor (LE)successor (TICT) model, ${ }^{11}$ but it has recently been shown that the TICT state can be formed directly from the Franck-Condon (FC) state on $\mathrm{S}_{2}$ through a conical intersection, corresponding to a nonadiabatic and nearly barrierless reaction route. ${ }^{11,26,27}$ The situation is even worse in TICT-free systems because experimental evaluation of the kinetic factors for a hypothetical torsional process is impossible. While theoretical modeling in search of the transition state and thus the reaction barrier might provide a solution, reliable computational methods remain to be established. As a result, the absence of TICT state formation is often intuitively attributed to a high-lying TICT state (e.g., $3 \mathrm{DMABN}^{18}$ ), and to date, the concept of thermodynamically allowed (i.e., exothermic) but kinetically inhibited (i.e., slow) $\mathrm{D}-\mathrm{A}$ torsional motion has not yet been demonstrated.

trans-Aminostilbenes, including DCS, are a special category of $\mathrm{D}-\mathrm{A}$ molecules that could undergo another type of torsional motion in the photoinduced ICT states: namely, the central double-bond torsion that leads to trans-cis photoisomerization.

(17) (a) Albert, I. D. L.; Marks, T. J.; Ratner, M. A. J. Am. Chem. Soc. 1997, 119, 3155-3156. (b) Albert, I. D. L.; Marks, T. J.; Ratner, M. A. J. Am. Chem. Soc. 1998, 120, 11174-11181. (c) Kang, H.; Facchetti, A.; Zhu, P.; Jiang, H.; Yang, Y.; Cariati, E.; Righetto, S.; Ugo, R.; Zuccaccia, C.; Macchioni, A.; Stern, C. L.; Liu, Z.; Ho, S.-T.; Marks, T. J. Angew. Chem. Int. Ed. 2005, 44, 7922-7925. (d) Kang, H.; Facchetti, A.; Jiang, H.; Cariati, E.; Righetto, S.; Ugo, R.; Zuccaccia, C.; Macchioni, A.; Stern, C. L.; Liu, Z.; Ho, S.-T.; Brown, E. C.; Ratner, M. A.; Marks, T. J. J. Am. Chem. Soc. 2007, 129, 3267-3286.

(18) Rettig, W.; Bliss, B.; Dirnberger, K. Chem. Phys. Lett. 1999, 305, 8-14

(19) (a) Jödicke, C. J.; Lüthi, H. P. J. Am. Chem. Soc. 2003, 125, 252-264. (b) Jödicke, C. J.; Lüthi, H. P. J. Chem. Phys. 2003, 119, 12852-12865.

(20) (a) Amatatsu, Y. Theor. Chem. Acc. 2000, 103, 445-450. (b) Amatatsu, Y. Chem. Phys. 2001, 274, 87-98. (c) Amatatsu, Y. J. Phys. Chem. A 2006, 110, 8736-8743.

(21) Gruen, H.; Görner, H. Z. Naturforsch. 1983, 38a, 928-936.

(22) (a) Safarzadeh-Amiri, A. Chem. Phys. Lett. 1986, 125, 272-278. (b) Rechthaler, K.; Köhler, G. Chem. Phys. Lett. 1996, 250, 152-158. (c) Eilers-König, N.; Kühne, T.; Schwarzer, D.; Vöhringer, P.; Schroeder, J. Chem. Phys. Lett. 1996, 253, 69-76. (d) Il'ichev, Y. V.; Kühnle, W.; Zachariasse, K. A. Chem. Phys. 1996, 211, 441-453. (e) Il'ichev, Y. V. Zachariasse, K. A. Ber. Bunsen-Ges. Phys. Chem. 1997, 101, 625-635. (f) Lewis, F. D.; Weigel, W. J. Phys. Chem. A 2000, 104, 8146-8153. (g) Kovalenko, S. A.; Schanz, R.; Senyushkina, T. A.; Ernsting, N. P. Phys. Chem. Chem. Phys. 2002, 4, 703-707. (h) Arzhantsev, S.; Zachariasse, K. A.; Maroncelli, M. J. Phys. Chem. A 2006, 110, 3454-3470.

(23) Yang, J.-S.; Liau, K.-L.; Hwang, C.-Y.; Wang, C.-M. J. Phys. Chem. A 2006, 110, 8003-8010

(24) Rappoport, D.; Furche, F. J. Am. Chem. Soc. 2004, 126, 1277-1284.

(25) (a) Minezawa, N.; Kato, S. J. Phys. Chem. A 2005, 109, 5445-5453. (b) Druzhinin, S. I.; Ernsting, N. P.; Kovalenko, S. A.; Lustres, L. P.; Senyushkina, T. A.; Zachariasse, K. A. J. Phys. Chem. A 2006, 110, 29552969.

(26) Fuss, W.; Pushpa, K. K.; Rettig, W.; Schmid, W. E.; Trushin, S. A Photochem. Photobiol. Sci. 2002, 1, 255-262.

(27) Gómez, I.; Reguero, M.; Boggio-Pasqua, M.; Robb, M. A. J. Am. Chem. Soc. 2005, 127, 7119-7129. 


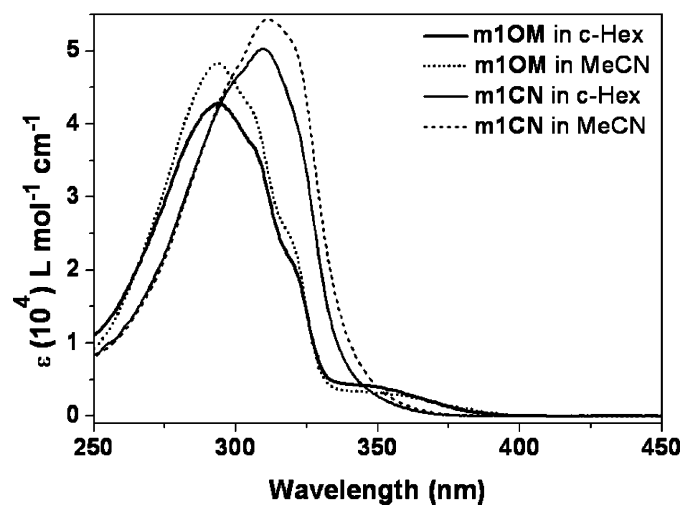

Figure 2. Electronic absorption spectra of $\mathbf{m 1 O M}$ and $\mathbf{m 1 C N}$ in cyclohexane $(c$-Hex) and acetonitrile $(\mathrm{MeCN})$.

The photoisomerization competes with fluorescence in accounting for the deactivation of excited trans-stilbenes. Unlike the case of the D-A single-bond torsion, the structural effects on the double-bond torsion are well documented. ${ }^{28-32}$ We have recently shown that the double-bond torsion does not couple with the single-bond torsion in trans-aminostilbenes, and thus, deactivation of the TICT state is mainly by heat. ${ }^{23,32}$ Therefore, formation of a TICT state for trans-aminostilbenes can be readily detected based on their solvent-dependent fluorescence $\left(\Phi_{\mathrm{f}}\right)$ and photoisomerization $\left(\Phi_{\mathrm{tc}}\right)$ quantum yields, and there is no need to know if the TICT state is fluorescent or which bond is twisted. ${ }^{23,32}$ With this advantage and the structural variability, trans-aminostilbenes are excellent candidates for gaining insights into the structural effects on the excited-state D-A single-bond torsional motions.

In this paper, we would like to address the meta vs para conjugation effect on TICT state formation through investigation of a series of trans-3-( $N$-arylamino)stilbenes $(\mathbf{m} \mathbf{1})$ and their ringbridged derivatives ( $\mathbf{m} \mathbf{2}$ and $\mathbf{m} \mathbf{3})$ and through comparison with the previously reported para isomers (p1). ${ }^{32}$ The results reported herein not only explicitly show that the degree of conjugation interactions in the ICT state plays an important role in TICT state formation but also provides the first experimental evidence for thermodynamically favorable but kinetically unfavorable D-A torsional motions. More specifically, unlike the TICTforming $\mathbf{p 1 C N}$, TICT state formation is negligible for $\mathbf{m 1 C N}$, although both compounds possess a low-lying TICT state. This argument is in part based on the fact that the truncated molecule CNDPA undergoes efficient TICT formation in acetonitrile, ${ }^{33}$ which is corroborated by the behavior of its $N$-methyl and ringbridged compounds CNDPAM and CNDPAB. Another example

(28) (a) Saltiel, J.; Charlton, J. L. Rearrangements in Ground and Excited States de Mayo, P., Ed.; Academic Press: New York, 1980; Vol. 3, pp 25-89. (b) Saltiel, J.; Sun, Y.-P. Photochromism, Molecules and Systems; Dürr, H., Bouas-Laurent, H., Eds.; Elsevier: Amsterdam, 1990, pp 64-164. (c) Waldeck, D. H. Chem. Rev. 1991, 91, 415-436. (d) Meier, H. Angew. Chem., Int. Ed. Engl. 1992, 31, 1399-1420. (f) Görner, H.; Kuhn, H. J. Adv. Photochem. 1995, 19, 1-117.

(29) (a) Lewis, F. D.; Kalgutkar, R. S ; Yang, J -S. J Am Chem Soc 1999 121, 12045-12053. (b) Lewis, F. D.; Weigel, W. J. Phys. Chem. A 2000, 104, 8146-8153. (c) Lewis, F. D.; Weigel, W.; Zuo, X. J. Phys. Chem. A 2001, 105, 4691-4696.

(30) (a) Yang, J.-S.; Chiou, S.-Y.; Liau, K.-L. J. Am. Chem. Soc. 2002, 124 2518-2527. (b) Yang, J.-S.; Wang, C.-M.; Hwang, C.-Y.; Liau, K.-L.; Chiou, S.-Y. Photochem. Photobiol. Sci. 2003, 2, 1225-1231.

(31) Yang, J.-S.; Liau, K.-L.; Tu, C.-W.; Hwang, C.-Y. J. Phys. Chem. A 2005, 109, 6450-6456.

(32) Yang, J.-S.; Liau, K.-L.; Wang, C.-M.; Hwang, C.-Y. J. Am. Chem. Soc. 2004, 126, 12325-12335.

(33) (a) Kapelle, S.; Rettig, W.; Lapouyade, R. Chem. Phys. Lett. 2001, 348 , 416-424. (b) Kapelle, S.; Rettig, W.; Lapouyade, R. Photochem. Photobiol. Sci. 2002, 1, 492-499. of conjugation-dependent TICT behavior is provided by the isomers m1Me and p1Me. Whereas m1Me undergoes TICT state formation in acetonitrile, aminostilbene p1Me is TICT free in spite of having a larger driving force for TICT formation. Implications of these results on the TICT dynamics of DCS and 3DMABN will also be addressed.

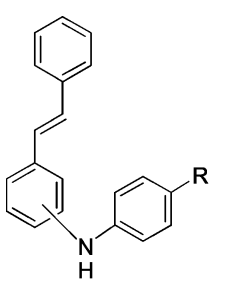

meta: $\mathbf{m} 1$ para: $\mathbf{p 1}$

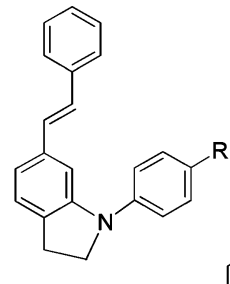

m2

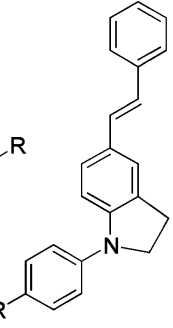

p2

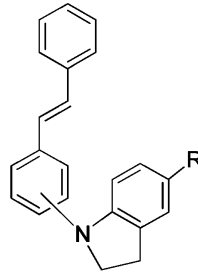

meta: $\mathbf{m} 3$ para: p3

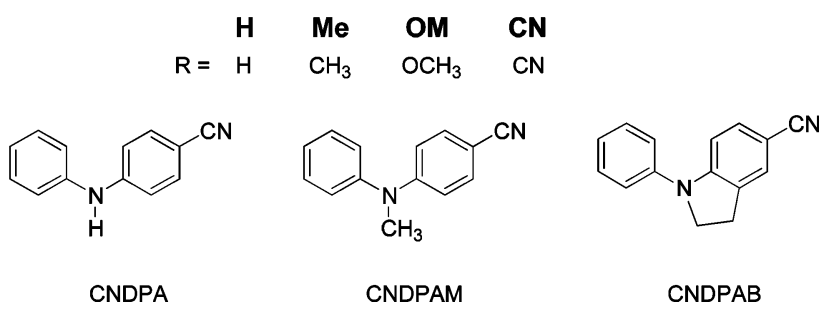

\section{Results and Discussion}

Electronic Spectra. The absorption spectra of $\mathbf{m 1 O M}$ and m1CN in cyclohexane and acetonitrile are shown in Figure 2. The spectra for $\mathbf{m} \mathbf{1 H}$ have been reported. ${ }^{31}$ Both the spectra of $\mathbf{m 1 H}$ and $\mathbf{m 1 M e}$ resemble those of $\mathbf{m 1 O M}$, where the most intense bands are located near $295 \mathrm{~nm}$ and there also exists a low-intensity broad shoulder near $340 \mathrm{~nm}$, corresponding to $\mathrm{S}_{0}$ $\rightarrow \mathrm{S}_{2}$ and $\mathrm{S}_{0} \rightarrow \mathrm{S}_{1}$ transitions, respectively. According to our previous studies on the " $m$-amino conjugation effect", 31 this can be attributed to band splitting as a result of configuration interactions (i.e., electronic coupling) between the meta-bridged subunits. Spectral deconvolution with Gaussian bands allows one to estimate the peak maxima $\left(\lambda_{\mathrm{abs}}\right)$ and oscillator strengths $(f)$ for the $\mathrm{S}_{0} \rightarrow \mathrm{S}_{1}$ transition. These data are presented in Table 1. In contrast, no distinct shoulder was observed for the spectra of $\mathbf{m 1 C N}$, although there is a significant tailing in the red edge of the absorption band. The absorption maxima $(310 \mathrm{~nm})$ are red shifted with respect to that for $\mathbf{m 1 O M}(294 \mathrm{~nm})$, but the red edges $(\sim 375 \mathrm{~nm})$ of the spectra are at shorter wavelength than those for $\mathbf{m 1 0 M}(\sim 400 \mathrm{~nm})$. Evidently, the band splitting is also present but weaker in $\mathbf{m 1 C N}$. Since the electron-donating amino group plays an important role in determining the magnitude of electronic coupling, ${ }^{6}$ the weaker band splitting in m1CN can be ascribed to the strong electron-withdrawing $\mathrm{CN}$ group that reduces the electron-donating ability of the anilino group. As a result, the 0,0 transitions derived from the intersection of normalized absorption and fluorescence spectra (vide infra) are at shorter wavelengths and the $f$ values are lower for $\mathbf{m} \mathbf{1 C N}$ than for the other three $\mathbf{m} \mathbf{1}$ derivatives (Table 1).

Figure 3 shows the fluorescence spectra of m1Me, m1OM, and $\mathbf{m 1 C N}$ in a variety of solvents. The corresponding spectra of $\mathbf{m 1 H}$ have been reported. ${ }^{31}$ The fluorescence spectra of $\mathbf{m} \mathbf{1}$ are structureless in both nonpolar and polar solvents, as observed for many other 3-aminostilbenes. ${ }^{29}$ The lack of well-resolved vibrational bands even in nonpolar cyclohexane solvent might 
Table 1. Maxima of UV Absorption ( $\left.\lambda_{\text {abs }}\right)$ and Fluorescence $\left(\lambda_{f}\right)$, Fluorescence-Band Half-Width $\left(\Delta v_{1 / 2}\right), 0,0$ Transition $\left(\lambda_{0,0}\right)$, Stokes Shifts $\left(\Delta v_{\mathrm{st}}\right)$, and Oscillator Strength $(f)$ for the $\mathrm{S}_{0} \rightarrow \mathrm{S}_{1}$ Band of $\mathbf{m} 1-\mathbf{m} 3, \mathbf{p} \mathbf{1}$, and CNDPAs in Cyclohexane $(c$-Hex) or Hexane $(\mathrm{Hex})$ and Acetonitrile $(\mathrm{MeCN})^{a}$

\begin{tabular}{|c|c|c|c|c|c|c|c|}
\hline compd & solvent & $\lambda_{\text {abs }}(n \mathrm{~nm})^{b}$ & $\lambda_{f}(\mathrm{~nm})^{c}$ & $\begin{array}{l}\Delta v_{1 / 2} \\
\left(\mathrm{~cm}^{-1}\right)\end{array}$ & $\begin{array}{c}\lambda_{0,0} \\
(\mathrm{~nm})^{d}\end{array}$ & $\begin{array}{c}\Delta v_{\text {st }} \\
\left(\mathrm{cm}^{-1}\right)^{e}\end{array}$ & $f^{\prime}$ \\
\hline \multirow[t]{2}{*}{ m1CN } & $c$-Hex & $310(349)$ & 397 & 4012 & 363 & 3464 & 0.02 \\
\hline & $\mathrm{MeCN}$ & 311 (348) & 434 & 4227 & 371 & 5694 & 0.03 \\
\hline \multirow[t]{2}{*}{$\mathbf{p} 1 \mathrm{CN}^{g}$} & Hex & 341 & 381 (399) & 2712 & 370 & 3079 & \\
\hline & $\mathrm{MeCN}$ & 352 & 425 [517] & 8086 & 387 & 4880 & \\
\hline \multirow[t]{2}{*}{ m1H } & $c$-Hex & 294 (335) & 403 & 3716 & 371 & 5037 & 0.10 \\
\hline & $\mathrm{MeCN}$ & 294 (336) & 473 & 4316 & 395 & 8620 & 0.08 \\
\hline \multirow[t]{2}{*}{ m1Me } & $c$-Hex & $294(341)$ & 411 & 3737 & 378 & 4995 & 0.07 \\
\hline & $\mathrm{MeCN}$ & $293(341)$ & 497 & 4763 & 399 & 9205 & 0.08 \\
\hline \multirow[t]{2}{*}{$\mathbf{p} 1 \mathbf{M e}^{g}$} & Hex & 349 & $385(402)$ & 2808 & 374 & 2679 & \\
\hline & $\mathrm{MeCN}$ & 354 & 457 & 3866 & 398 & 6367 & \\
\hline \multirow[t]{2}{*}{ m1OM } & $c$-Hex & $294(342)$ & 417 & 3674 & 382 & 5259 & 0.08 \\
\hline & $\mathrm{MeCN}$ & $293(343)$ & $>650$ & & & & 0.08 \\
\hline \multirow[t]{2}{*}{ m2Me } & $c$-Hex & $301(363)$ & (415) 436 & 3625 & 400 & 4612 & 0.12 \\
\hline & $\mathrm{MeCN}$ & $302(364)$ & 500 & 3980 & 423 & 7473 & 0.14 \\
\hline \multirow[t]{2}{*}{$\mathrm{m} 2 \mathrm{OM}$} & $c$-Hex & 299 (364) & (422) 444 & 3495 & 405 & 4950 & 0.11 \\
\hline & $\mathrm{MeCN}$ & $300(366)$ & 525 & 4179 & 433 & 8275 & 0.13 \\
\hline \multirow[t]{2}{*}{$\mathrm{m} 3 \mathrm{CN}$} & $c$-Hex & $310(350)$ & 399 & 3798 & 368 & 3509 & 0.03 \\
\hline & $\mathrm{MeCN}$ & $326(352)$ & 479 & 4475 & 387 & 7532 & 0.03 \\
\hline \multirow[t]{2}{*}{ CNDPA } & $c$-Hex & 302 & 363 & 3901 & 331 & 5564 & \\
\hline & $\mathrm{MeCN}$ & 313 & 489 & 5146 & 361 & 11499 & \\
\hline \multirow{2}{*}{ CNDPAM } & $c$-Hex & 297 & 383 & 3714 & 348 & 7560 & \\
\hline & $\mathrm{MeCN}$ & 300 & 501 & 4665 & 364 & 13373 & \\
\hline \multirow[t]{2}{*}{ CNDPAB } & $c$-Hex & 324 & 356 & 2881 & 343 & 2774 & \\
\hline & $\mathrm{MeCN}$ & 331 & 392 & 4249 & 356 & 4701 & \\
\hline
\end{tabular}

${ }^{a}$ Fluorescence data are from corrected spectra. ${ }^{b}$ The peak maxima of the long-wavelength shoulders are given in parentheses. ${ }^{c}$ The vibronic shoulders are given in parentheses, and the second emission band is given in brackets. ${ }^{d}$ The value of $\lambda_{0,0}$ was obtained from the intersection of normalized absorption and fluorescence spectra. ${ }^{e} \Delta v_{\mathrm{st}}=v_{\mathrm{abs}}\left(\mathrm{S}_{0} \rightarrow \mathrm{S}_{1}\right)-$ $v_{\mathrm{f} .}{ }^{f} f=4.3 \times 10^{-9} \int(v) \mathrm{d} v .{ }^{g}$ From ref 32.

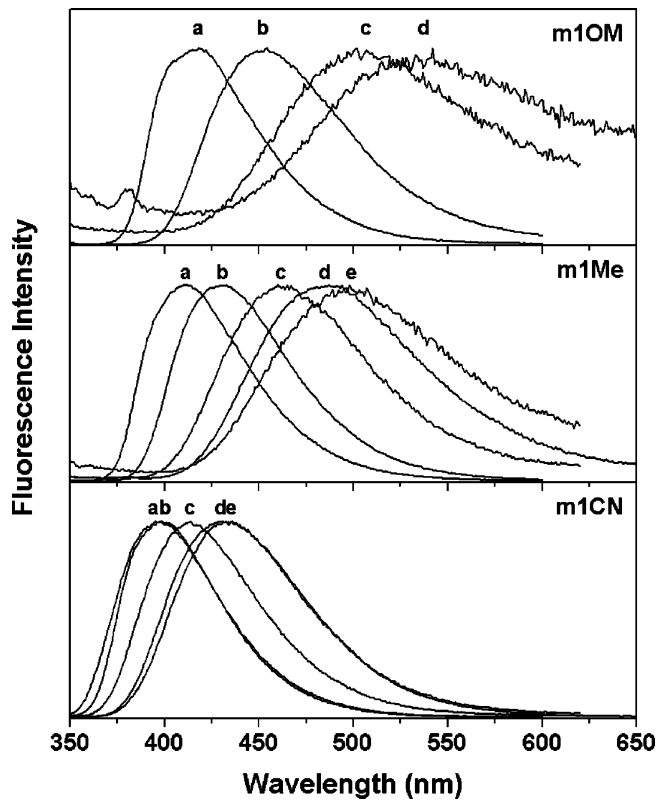

Figure 3. Normalized fluorescence spectra of $\mathbf{m 1 O M}, \mathbf{m} 1 \mathrm{Me}$, and $\mathbf{m 1 C N}$ in (a) cyclohexane, (b) toluene, (c) dichloromethane, (d) acetone, and (e) acetonitrile.

be in part due to a less planar conformation about the stilbenylanilino $\mathrm{C}-\mathrm{N}$ bond because the fluorescence spectrum for the ring-bridged derivatives $\mathbf{m} \mathbf{2 M e}$ and $\mathbf{m} \mathbf{2 O M}$ display vibrational bands in cyclohexane (Table 1 and Figure S4). Unlike the absorption spectra, the fluorescence maxima show a considerable red shift on going from cyclohexane to acetonitrile, indicating
Table 2. Ground- and Excited-State Dipole Moments for $\mathbf{m} 1-\mathbf{m} 3$ and CNDPAs

\begin{tabular}{lllcc}
\hline \multicolumn{1}{c}{ compound } & $a(\AA)^{a}$ & $m_{\mathrm{f}}\left(\mathrm{cm}^{-1}\right)^{b}$ & $\mu_{\mathrm{g}}(\mathrm{D})^{c}$ & $\mu_{\mathrm{e}}(\mathrm{D})^{d}$ \\
\hline $\mathbf{m 1 C N}$ & 4.90 & 7732 & 4.43 & $8.5 \pm 0.5^{e}\left(9.1^{f}\right)$ \\
$\mathbf{m} 1 \mathbf{H}$ & 4.76 & 11524 & 0.89 & $11.5 \pm 0.6(10.8)$ \\
$\mathbf{m 1 M e}$ & 4.84 & 12901 & 1.00 & $12.6 \pm 0.5(11.8)$ \\
$\mathbf{m} 1 \mathbf{O M}$ & 4.93 & 16443 & 0.73 & $14.3 \pm 0.8(13.6)$ \\
$\mathbf{m} 2 \mathbf{M e}$ & 4.98 & 8822 & 1.17 & $11.0 \pm 0.5$ \\
$\mathbf{m} 2 \mathbf{M}$ & 5.06 & 10849 & 1.67 & $12.7 \pm 0.5(11.7)$ \\
$\mathbf{m 3 C N}$ & 5.04 & 12908 & 4.21 & $11.8 \pm 0.7(8.7)$ \\
CNDPA & 4.25 & 20788 & 4.55 & $15.1 \pm 0.7$ \\
CNDPAM & 4.35 & 18995 & 5.12 & $15.3 \pm 0.6$ \\
CNDPAB & 4.44 & 8061 & 4.32 & $10.8 \pm 0.6$ \\
\hline
\end{tabular}

${ }^{a}$ Onsager radius from eq 3 with $d=1.0 \mathrm{~g} / \mathrm{cm}^{3}$ for all cases. ${ }^{b}$ Calculated based on eq 1. ${ }^{c}$ Calculated by use of AM1. ${ }^{d}$ Value in the parentheses is the dipole moment of the para isomer; data from ref $32 .{ }^{e}$ Calculated with $-0.5 \mu_{g}{ }^{f}$ Dipole moment of the PICT state of $\mathbf{p 1 C N}$

a strong ICT character for the $\mathrm{S}_{1}$ state of $\mathbf{m} 1$. It should be noted that the spectra in polar solvents are relatively broader for m1OM and $\mathbf{m 1 M e}$ than $\mathbf{m 1 C N}$. The fluorescence maxima $\left(\lambda_{\mathrm{f}}\right)$, the half-bandwidth $\left(\Delta \nu_{1 / 2}\right)$, and the Stokes shift $\left(\Delta v_{\mathrm{st}}\right)$ are reported in Table 1.

To estimate the dipole moment of the fluorescing state $\left(\mu_{\mathrm{e}}\right)$, the slopes $\left(m_{\mathrm{f}}\right)$ of the solvatofluorochromic plots of the energies of the fluorescence maxima against the solvent parameter $\Delta f$ (Figures $\mathrm{S} 1-\mathrm{S} 2$ ) were obtained according to eq $1^{34}$

$$
\left.v_{\mathrm{f}}=-\left[\left(1 / 4 \pi \epsilon_{0}\right)\left(2 / h c a^{3}\right)\right]\left[\mu_{\mathrm{e}}\left(\mu_{\mathrm{e}}-\mu_{\mathrm{g}}\right)\right]\right] \cdot \Delta f+\text { constant }
$$

where

$$
\Delta f=(\epsilon-1) /(2 \epsilon+1)-0.5\left(n^{2}-1\right) /\left(2 n^{2}+1\right)
$$

and

$$
a=(3 \mathrm{M} / 4 N \pi d)^{1 / 3}
$$

where $v_{\mathrm{f}}$ is the fluorescence maximum, $\mu_{\mathrm{g}}$ is the ground-state dipole moment, $a$ is the solvent cavity (Onsager) radius, which was derived from Avogadro's number $(N)$, molecular weight $(\mathrm{M})$, and density $(d)$, and $\epsilon, \epsilon_{0}$, and $n$ are the solvent dielectric constant, vacuum permittivity, and solvent refractive index, respectively. The value of $\mu_{\mathrm{g}}$ was calculated using the MOPACAM1 algorithm. ${ }^{35}$ The calculated values of $a, m_{\mathrm{f}}, \mu_{\mathrm{e}}$, and $\mu_{\mathrm{g}}$ for $\mathbf{m} \mathbf{1}$ are summarized in Table 2. The relative values of $m_{\mathrm{f}}$ and thus $\mu_{\mathrm{e}}$ are $\mathbf{m 1 O M}>\mathbf{m 1 M e}>\mathbf{m 1 H}>\mathbf{m 1 C N}$, as expected based on the relative electron-donating ability of the anilino groups. It should be noted that the ground- and excited-state dipoles in $\mathbf{m 1 C N}$ are in different directions, which are amino $\mathrm{N} \rightarrow$ benzonitrilo and amino $\mathrm{N} \rightarrow$ stilbenyl, respectively. Assuming that the angle between the ground- and excited-state dipoles of $\mathbf{m} 1 \mathbf{C N}$ is ca. $120^{\circ}$, the calculated ground-state dipole would have a component vector of $0.5 \mu_{\mathrm{g}}$ (i.e., $\cos \left(120^{\circ}\right) \mu_{\mathrm{g}}$ ) in a direction opposite to the excited-state dipole. Accordingly, a negative value of $-0.5 \mu_{\mathrm{g}}$ was adopted for eq 1 in calculating $\mu_{\mathrm{e}}$ for $\mathbf{m 1 C N}$, resembling the case of $\mathbf{p} 1 \mathbf{C N}{ }^{32}$

Upon ring bridging for $\mathbf{m} \mathbf{1}$ (i.e., derivatives $\mathbf{m} 20 \mathrm{M}, \mathbf{m} 2 \mathrm{Me}$, and $\mathbf{m 3 C N}$ ), noticeable changes in the electronic spectra are observed. For $\mathbf{m} \mathbf{2 O M}$ and $\mathbf{m} \mathbf{2 M e}$, both the first $\left(\mathrm{S}_{0} \rightarrow \mathrm{S}_{1}\right)$ and the second $\left(\mathrm{S}_{0} \rightarrow \mathrm{S}_{2}\right)$ absorption maxima shift toward the red,

(34) Baumann, W.; Bischof, H.; Fröhling, J.-C.; Brittinger, C.; Rettig, W Rotkiewicz, K. J. Photochem. Photobiol. A: Chem. 1992, 64, 49-72.

(35) Dewar, M. J. S.; Zoebisch, E. G.; Healy, E. F.; Stewart, J. J. P. J. Am. Chem. Soc. 1985, 107, 3902-3909. 


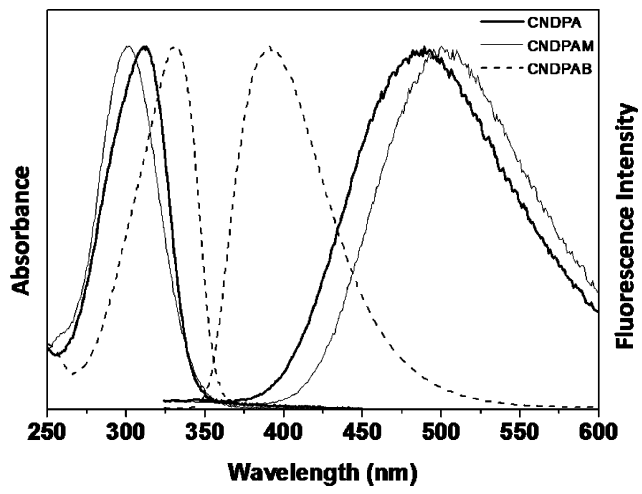

Figure 4. Normalized absorption and fluorescence spectra of CNDPA, CNDPAM, and CNDPAB in acetonitrile.

which is as expected due to the additional $N$-ethylene group (Table 1, Figure S3). We also note that the relative intensity for the first vs the second band and the magnitude of band splitting in $\mathbf{m} \mathbf{2 O M}$ and $\mathbf{m} 2 \mathbf{M e}$ are slightly larger ( $\sim 3 \%$ more for the relative intensity and $\sim 1000 \mathrm{~cm}^{-1}$ more between the two bands) than those in the parent m1OM and m1Me, respectively. Evidently, increasing the electron-donating ability and planarity of the amino group enhances the electronic coupling through the $m$-Ph bridge. Furthermore, ring bridging leads to more structured fluorescence spectra in cyclohexane (Figure S4), indicating that the structureless fluorescence spectra of trans-3-aminostilbenes ${ }^{31,36}$ in nonpolar solvents is associated with the degree of $\mathrm{D}-\mathrm{A}$ coplanarity in the fluorescing state. Moreover, the fluorescence spectra in polar solvents become sharper for the ring-bridged derivatives. Because of the different ring-bridging position, the resulting changes in both absorption and fluorescence spectra on going from $\mathbf{~} 1 \mathbf{C N}$ to $\mathbf{~} \mathbf{3 C N}$ appear to be smaller. In addition, it is interesting to note that the difference in the ring-bridging position results in a different effect on the excited-state dipole moment, where it is increased on going from $\mathbf{m 1 C N}$ to $\mathbf{m} \mathbf{3 C N}$ but decreased on going from m1Me and $\mathbf{m 1 O M}$ to $\mathbf{m 2 M e}$ and $\mathbf{m 2 O M}$ (Table 2). The smaller excited-state dipole moment for $\mathbf{m} \mathbf{2}$ vs $\mathbf{m} \mathbf{1}$ appears to be in conflict with the stronger electronic coupling and donor strength. Evidently, the less planar structure in the fluorescing state of $\mathbf{m} \mathbf{1}$ promotes a larger degree of charge separation and thus a larger dipole moment.

Compound CNDPA is a truncated molecule of $\mathbf{m 1 C N}$ and p1CN by removing the styryl group. The fluorescence spectrum of CNDPA in acetonitrile has been reported, ${ }^{33}$ but more detailed spectroscopic data were not presented. As such, we carried out studies on CNDPA as well as its $N$-methyl and ring-bridged derivatives CNDPAM and CNDPAB. Figure 4 shows the normalized absorption and fluorescence spectra of CNDPA, CNDPAM, and CNDPAB in acetonitrile, and more spectroscopic data are shown in Table 1. It is interesting to note that the absorption maximum is CNDPAB $>$ CNDPA $>$ CNDPAM in both cyclohexane and acetonitrile, but their fluorescence maxima show an opposite order in acetonitrile (i.e., CNDPAM $>$ CNDPA > CNDPAB) and an order of CNDPAB > CNDPAM > CNDPA in cyclohexane. The unexpected blue shift of the absorption maximum for CNDPAM vs CNDPA clearly shows that the absorption maximum is very sensitive to

(36) Karabunarliev, S.; Baumgarten, M.; Tyutyulkov, N.; Müllen, K. J. Phys. Chem. 1994, 98, 11892-11901.
Table 3. Quantum Yields for Fluorescence $\left(\Phi_{\mathrm{f}}\right)$ and Photoisomerization $\left(\Phi_{\mathrm{tc}}\right)$, Fluorescence Decay Times $\left(\tau_{f}\right)$, and Rate Constants for Fluorescence Decay $\left(k_{f}\right)$ and Nonradiative Decay $\left(k_{\mathrm{nr}}\right)$ for $\mathbf{m} \mathbf{1}-\mathbf{m} \mathbf{3}, \mathbf{p} \mathbf{1}$, and CNDPAs in Solution

\begin{tabular}{|c|c|c|c|c|c|c|}
\hline compd & solvent & $\Phi_{\mathrm{f}}$ & $\Phi_{10}{ }^{a}$ & $\tau_{\sharp} / n s^{b}$ & $k_{\mathrm{f}}\left(10^{7} \mathrm{~s}^{-1}\right)$ & $k_{n r}\left(10^{7} s^{-1}\right)$ \\
\hline \multirow[t]{4}{*}{ m1CN } & $c$-Hex & 0.52 & 0.23 & 10.1 & 5.1 & 4.7 \\
\hline & THF & 0.49 & & & & \\
\hline & $\mathrm{CH}_{2} \mathrm{Cl}_{2}$ & 0.42 & 0.27 & 8.6 & 4.9 & 6.8 \\
\hline & $\mathrm{MeCN}$ & 0.37 & 0.32 & 14.0 & 2.6 & 4.5 \\
\hline \multirow[t]{2}{*}{$\mathbf{p} 1 \mathbf{C} \mathbf{N}^{c}$} & Hex & 0.75 & 0.16 & 1.30 & 58 & 19 \\
\hline & $\mathrm{MeCN}$ & 0.015 & $0.04^{d}$ & 0.84 & 1.8 & 117 \\
\hline \multirow[t]{4}{*}{$\mathbf{m} 1 \mathbf{H}^{e}$} & $c$-Hex & 0.57 & $0.23^{d}$ & $14.8^{d}$ & $3.8^{d}$ & $2.9^{d}$ \\
\hline & THF & 0.32 & & & & \\
\hline & $\mathrm{CH}_{2} \mathrm{Cl}_{2}$ & 0.29 & $0.38^{c}$ & $9.2^{d}$ & $3.1^{d}$ & $7.7^{d}$ \\
\hline & $\mathrm{MeCN}$ & 0.17 & $0.42^{d}$ & $10.0^{d}$ & $1.7^{d}$ & $8.3^{d}$ \\
\hline \multirow[t]{4}{*}{ m1Me } & $c$-Hex & 0.56 & 0.22 & 13.4 & 4.2 & 3.3 \\
\hline & THF & 0.22 & & & & \\
\hline & $\mathrm{CH}_{2} \mathrm{Cl}_{2}$ & 0.18 & 0.41 & 7.7 & 2.3 & 10.7 \\
\hline & $\mathrm{MeCN}$ & 0.08 & 0.25 & 6.1 & 1.3 & 15.0 \\
\hline \multirow[t]{2}{*}{$\mathbf{p} 1 \mathrm{Me}^{c}$} & Hex & 0.53 & & 0.96 & 55 & 49 \\
\hline & $\mathrm{MeCN}$ & 0.41 & $0.27^{d}$ & 1.75 & 23 & 34 \\
\hline \multirow[t]{4}{*}{ m1OM } & $c$-Hex & 0.48 & 0.25 & 13.4 & 3.6 & 3.9 \\
\hline & THF & 0.07 & 0.29 & 5.0 & 1.4 & 18.6 \\
\hline & $\mathrm{CH}_{2} \mathrm{Cl}_{2}$ & 0.05 & 0.20 & 3.6 & 1.4 & 26.1 \\
\hline & $\mathrm{MeCN}$ & $<0.003$ & 0.04 & & & \\
\hline \multirow[t]{3}{*}{ m2Me } & $c$-Hex & 0.65 & 0.15 & 8.9 & 7.3 & 3.9 \\
\hline & $\mathrm{CH}_{2} \mathrm{Cl}_{2}$ & 0.31 & & 6.5 & 4.8 & 10.6 \\
\hline & $\mathrm{MeCN}$ & 0.47 & 0.25 & 14.3 & 3.3 & 3.7 \\
\hline \multirow[t]{3}{*}{ m2OM } & $c$-Hex & 0.73 & 0.18 & 10.3 & 7.1 & 2.6 \\
\hline & $\mathrm{CH}_{2} \mathrm{Cl}_{2}$ & 0.35 & 0.31 & 10.1 & 3.5 & 6.5 \\
\hline & $\mathrm{MeCN}$ & 0.37 & & 14.1 & 2.6 & 4.5 \\
\hline \multirow[t]{3}{*}{$\mathrm{m} 3 \mathrm{CN}$} & $c$-Hex & 0.39 & 0.27 & 11.3 & 3.5 & 5.4 \\
\hline & $\mathrm{CH}_{2} \mathrm{Cl}_{2}$ & 0.24 & & 10.5 & 2.3 & 7.3 \\
\hline & $\mathrm{MeCN}$ & 0.14 & 0.40 & 9.8 & 1.4 & 8.8 \\
\hline \multirow[t]{2}{*}{ CNDPA } & $c$-Hex & 0.31 & & 2.8 & 11.1 & 24.6 \\
\hline & $\mathrm{MeCN}$ & 0.14 & & 6.8 & 2.1 & 12.6 \\
\hline \multirow[t]{2}{*}{ CNDPAM } & $c$-Hex & 0.34 & & 4.3 & 7.9 & 15.3 \\
\hline & $\mathrm{MeCN}$ & 0.14 & & 9.9 & 1.4 & 8.7 \\
\hline \multirow[t]{2}{*}{ CNDPAB } & $c$-Hex & 0.69 & & 2.3 & 30.0 & 13.5 \\
\hline & $\mathrm{MeCN}$ & 0.86 & & 2.9 & 29.7 & 4.8 \\
\hline
\end{tabular}

${ }^{a}$ Containing $10 \%$ THF when determined in cyclohexane and acetonitrile by reason of solubility. ${ }^{b}$ The value of $\tau_{\mathrm{f}}$ was determined with excitation and emission around the spectral maxima, unless otherwise noted. ${ }^{c}$ Data from ref $32 .{ }^{d}$ Data from this work. ${ }^{e}$ Data from ref 31 .

the planarity of the molecule. In other words, the additional $\mathrm{N}$-methyl group in CNDPAM increases the donor strength but concomitantly imposes larger steric demand that reduces the coplanarity of the two phenyl rings. The significantly red-shifted fluorescence spectrum for CNDPA vs CNDPAB in acetonitrile but not in cyclohexane indicates that the nature of the fluorescing state of CNDPA is different in these two solvents (i.e., TICT vs PICT, vide infra). It should also be noted that the dipole moment for the fluorescing state is much larger for CNDPA and CNDPAM than for CNDPAB (Table 2).

Quantum Yields and Lifetimes. Fluorescence quantum yields for $\mathbf{m} \mathbf{1}$ were determined in cyclohexane, THF, dichloromethane, and acetonitrile. As shown in Table 3, all four species are strongly fluorescent in cyclohexane, but the values of $\Phi_{\mathrm{f}}$ decrease in more polar solvents. Compounds m1OM and m1CN display the most and the least sensitive dependence of $\Phi_{\mathrm{f}}$ on the solvent polarity, respectively (i.e., $\mathbf{m 1 O M}>\mathbf{m} 1 \mathbf{M e}$ $>$ m1H $>$ m1CN).

Quantum yields for trans $\rightarrow$ cis photoisomerization for $\mathbf{m} \mathbf{1}$ in selected solvents are also reported in Table 3. It is well known that photoisomerization of trans-stilbenes can occur via the singlet $\left({ }^{1} t^{*}\right)$ and triplet $\left({ }^{3} t^{*}\right)$ state. ${ }^{28}$ Either decay pathway involves an intermediate perpendicular state $\left({ }^{1} \mathrm{p}^{*}\right.$ or $\left.{ }^{3} \mathrm{p}^{*}\right)$ located at the conical intersection from which a state jump can lead to 
the trans or cis isomer with a similar probability (i.e., $\sim 50 \%$ ). Whereas the process of ${ }^{1} \mathrm{t}^{*} \rightarrow \mathrm{p}^{*}$ involves a thermal barrier, it is essentially barrierless for the process of ${ }^{3} \mathrm{t}^{*} \rightarrow{ }^{3} \mathrm{p}^{*}$. The latter in turn suggests that nearly all the intersystem crossing processes ${ }_{1} t^{*} \rightarrow{ }^{3} t^{*}$ would lead to the double-bond torsion. As a result, the doubled amount of the determined trans $\rightarrow$ cis photoisomerization quantum yield $\left(\Phi_{\mathrm{tc}}\right)$ would approximately correspond to the sum of the quantum yields for singlet-state double-bond torsion $\left(\Phi_{\mathrm{d}}\right)$ and $\mathrm{S}_{1} \rightarrow \mathrm{T}_{1}$ intersystem crossing $\left(\Phi_{\mathrm{isc}}\right)$ : namely, $2 \Phi_{\mathrm{tc}}=\Phi_{\mathrm{d}}+\Phi_{\mathrm{isc}}$. Previous studies have shown that trans-4aminostilbenes mainly adopt the singlet mechanism (i.e., $2 \Phi_{\mathrm{tc}}$ $\approx \Phi_{\mathrm{d}}$ ) but the triplet mechanism predominates in trans-3aminostilbenes (i.e., $2 \Phi_{\mathrm{tc}} \approx \Phi_{\text {isc }}$ ) due to a large singlet-state torsional barrier. ${ }^{29-32}$ Disregarding the exact photoisomerization mechanism, the value of $\Phi_{\mathrm{f}}+2 \Phi_{\mathrm{tc}}$ allows one to determine if new decay channels other than fluorescence and photoisomerization are present for ${ }^{1} \mathrm{t}^{*}$. As shown in Table 3, except for $\mathbf{m 1 M e}$ in acetonitrile and $\mathbf{m 1 O M}$ in THF or more polar solvents, the value of $\Phi_{\mathrm{f}}+2 \Phi_{\mathrm{tc}}$ is within the experimental error of 1.0 for $\mathbf{m} \mathbf{1}$, indicating that new decay pathways are negligible for the latter cases but should be taken into account for the former cases.

The values of $\Phi_{\mathrm{f}}$ and $\Phi_{\mathrm{tc}}$ for the ring-bridged aminostilbenes $\mathbf{m} \mathbf{2 O M}, \mathbf{m} \mathbf{2 M e}$, and $\mathbf{m} \mathbf{3 C N}$ are also reported in Table 3. Unlike m1OM and m1Me that possess a value of $\Phi_{\mathrm{f}}+2 \Phi_{\mathrm{tc}}$ much less than 1.0 in polar solvents, all three ring-bridged compounds conform to $\Phi_{\mathrm{f}}+2 \Phi_{\mathrm{tc}} \approx 1.0$ in both nonpolar and polar solvents.

The room-temperature fluorescence lifetimes $\left(\tau_{\mathrm{f}}\right)$ determined with excitation and emission wavelengths around the spectral maxima for $\mathbf{m} \mathbf{1}-\mathbf{m} \mathbf{3}$ in selected solvents are provided in Table 3. All the decays can be well fit by single-exponential functions, although more than one planar conformer is expected for all cases. Table 3 also shows the rate constants for fluorescence $\left(k_{\mathrm{f}}=\Phi_{\mathrm{f}} \tau_{\mathrm{f}}^{-1}\right)$ and the overall nonradiative deactivation processes $\left(k_{\mathrm{nr}}=\left(1-\Phi_{\mathrm{f}}\right) / \tau_{\mathrm{f}}^{-1}\right)$. Both features of long decay times $(>8$ $\mathrm{ns})$ in cyclohexane and lower $k_{\mathrm{f}}$ values in more polar solvents for $\mathbf{m} \mathbf{1}-\mathbf{m} \mathbf{3}$ resemble the other trans-3-aminostilbenes. ${ }^{29,31}$ However, upon monitoring at the red edge of the fluorescence spectra, dual exponential decays were observed for $\mathbf{m 1 M e}$ and m1OM in polar solvents such as dichloromethane and acetonitrile (Table S1). For example, the fluorescence maximum of $\mathbf{m 1 M e}$ in acetonitrile is at $497 \mathrm{~nm}$, and a single decay time of $6.1 \mathrm{~ns}$ was obtained at 500, 525, and $550 \mathrm{~nm}$. However, at 575 $\mathrm{nm}$, biexponential fitting was required and the second decay time is a shorter lived component $(0.05 \mathrm{~ns})$ with a preexponential of $\sim 0.2$. Since the decay time is near the time resolution of our instrument $(0.1 \mathrm{~ns})$, it should be viewed as approximate. Likewise, a shorter lived component $(\sim 0.1 \mathrm{~ns})$ was detected for $\mathbf{m 1 O M}$ in dichloromethane upon monitoring at longer emission wavelength (>575 nm). This shorter-lived component is of extremely weak fluorescence since it contributes less than $2 \%$ of the fluorescence even at the fluorescence tail of the longer lived component. The longer and shorter lived components could be attributed to the PICT and TICT states, respectively (vide intra).

Table 3 also shows the values of $\Phi_{\mathrm{f}}$ and $\tau_{\mathrm{f}}$ for CNDPA, CNDPAM, and CNDPAB in cyclohexane and acetonitrile. Both CNDPA and CNDPAM possess a larger $\Phi_{\mathrm{f}}$ value in cyclohexane vs acetonitrile, but the opposite is true for CNDPAB. In addition, the value of $\tau_{\mathrm{f}}$ is much larger in acetonitrile vs
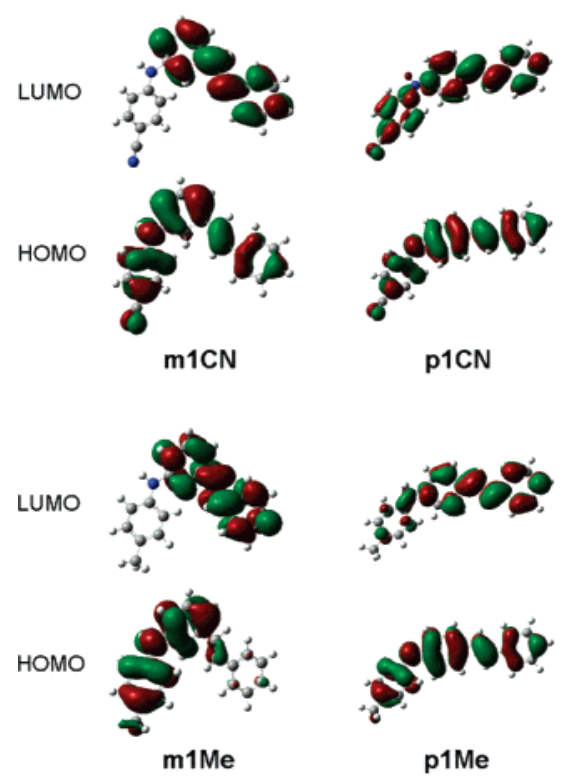

Figure 5. Frontier molecular orbital plots (B3LYP/6-31G(d,p)) of optimized structures of m1CN, p1CN, m1Me, and p1Me.

cyclohexane for CNDPA and CNDPAM but it is similar for CNDPAB. As a result, the $k_{\mathrm{f}}$ value is reduced by more than 5 -fold for the former two species on going from cyclohexane to acetonitrile, but there is no change for CNDPAB. In conjunction with the fluorescence spectra (vide supra), our results support the previous TICT argument for CNDPA. ${ }^{33}$ In other words, the observed fluorescence of CNDPA and CNDPAM in acetonitrile is almost entirely from their TICT state, which results from the twisting of the benzonitrilo-dimethylamino $\mathrm{C}-\mathrm{N}$ bond, but the ICT state for them in cyclohexane should be planar (i.e., PICT), as is the case of the ring-bridged CNDPAB.

Conjugation Interactions in $\mathbf{m} 1$ vs $\mathbf{p} 1$. The spectroscopic data, excited-state dipole moments, and quantum yields for fluorescence and trans $\rightarrow$ cis isomerization for $\mathbf{p} \mathbf{1}-\mathbf{p} \mathbf{3}$ have previously been reported. ${ }^{32}$ To address the relative conjugation (charge-delocalization) interactions in $\mathbf{m} \mathbf{1}$ vs $\mathbf{p} \mathbf{1}$, some of these data along with a couple of new data for $\mathbf{p 1}$, particularly $\mathbf{p 1 C N}$ and p1Me, are shown in Tables $1-3$. In addition, the DFT (B3LYP level of theory, ${ }^{37}$ 6-31G(d,p) basis set)-derived frontier molecular orbitals (FMOs) of m1CN, p1CN, m1Me, and p1Me are shown in Figure 5.

As reflected by the more localized absorption bands ( $\sim 295$ $\mathrm{nm}$ ) vs the single-intense long-wavelength absorption band of charge-transfer character for $\mathbf{m} \mathbf{1}$ vs $\mathbf{p 1}$, the ground-state conjugation interaction is as expected much weaker in the meta isomers. However, the presence of a low-intensity shoulder at longer wavelengths for $\mathbf{m} \mathbf{1}$ indicates the presence of electronic coupling between the $m$-Ph-bridged subunits. Such an electronic coupling increases with increasing electron-donating ability of the anilino group (vide supra). In the excited state, the comparable dipole moments for $\mathbf{m} \mathbf{1}$ and $\mathbf{p} \mathbf{1}$ (Table 2) suggest that the charge-separated ICT process in the meta isomers is as efficient as that in the para isomers. However, the significantly longer fluorescence lifetimes and lower fluorescence rate constants for $\mathbf{m} \mathbf{1}$ vs $\mathbf{p} \mathbf{1}$ indicate a much slower charge-

(37) (a) Lee, C.; Yang, W.; Parr, R. G. Phys. Rev. B 1988, 37, 785-789. (b) Becke, A. D. J. Chem. Phys. 1993, 98, 5648-5652. 
recombination process. This behavior resembles the larger $\mathrm{D}-\mathrm{A}$ systems recently reported by Thompson et al. ${ }^{7}$ and imposes an important effect on the molecular bonding character and thus the D-A torsional kinetics (vide infra). A weaker conjugation interaction for $\mathbf{m} \mathbf{1}$ vs $\mathbf{p} \mathbf{1}$ is also reflected by their FMOs, where the HOMO and LUMO of both $\mathbf{p 1 C N}$ and p1Me are delocalized, but the LUMOs of $\mathbf{m 1 C N}$ and $\mathbf{m 1 M e}$ are localized at the stilbene moiety, and their HOMOs are slightly localized at the diarylamino group.

Propensity of TICT Formation. We recently reported a simple guideline based on the values of $\Phi_{\mathrm{f}}$ and $\Phi_{\mathrm{tc}}$ for judging whether a TICT state is actively invoked in the excited decay of aminostilbenes. ${ }^{23,32}$ To claim an important TICT state formation, two phenomena should be observed: (1) the value of $\Phi_{\mathrm{f}}$ should be significantly smaller in polar vs nonpolar solvents, since the propensity of TICT state formation is larger in more polar solvents and the fluorescence quantum yield for TICT states is much lower than the precursor PICT state; (2) fluorescence and trans-cis photoisomerization cannot account for all the decay processes (i.e., $\Phi_{\mathrm{f}}+2 \Phi_{\mathrm{tc}} \ll 1.0$ ) because the process of photoisomerization is essentially decoupled with the TICT state deactivating processes. For example, $\mathbf{p 1 C N}$ has been shown to form a DMABN-like TICT state by twisting the benzonitrilo group in solvents more polar than THF. ${ }^{32}$ The $\Phi_{\mathrm{f}}$ value decreases by as much as 50 fold on going from hexane (0.75) to acetonitrile (0.015). In addition, the value of $\Phi_{\mathrm{f}}+$ $2 \Phi_{\text {tc }}$ for $\mathbf{p 1 C N}$ in hexane is 1.07 but only 0.095 in acetonitrile (Table 3). More evidence for TICT state formation of $\mathbf{p 1 C N}$ includes (a) the observation of PICT-TICT dual fluorescence in acetonitrile, (b) a significant reduction in the fluorescence rate constant $\left(k_{\mathrm{f}}\right)$ on going from hexane $\left(5.8 \times 10^{8} \mathrm{~s}^{-1}\right)$ to acetonitrile $\left(2.0 \times 10^{7} \mathrm{~s}^{-1}\right)$, (c) the dual fluorescence disappears and normal deactivating mode for trans-stilbenes (i.e., $\Phi_{\mathrm{f}}+$ $2 \Phi_{\mathrm{tc}} \approx 1.0$ ) recovered when the torsional motion is inhibited through constrained ring bridging between the $\mathrm{D}$ and $\mathrm{A}$ groups (i.e., p3CN), and (d) the fluorescence intensity increases upon raising the temperature. ${ }^{32}$ However, it should be noted that observation of a steady-state dual fluorescence (i.e., item a) is not a requirement for claiming formation of a TICT state because the TICT fluorescence could be extremely weak (vide infra). The evidence in item c not only confirms TICT state formation but also specifies the bond that is responsible for the torsional motion.

On the basis of the above guidelines we can readily conclude that TICT formation is negligible for $\mathbf{m 1 C N}$ in both cyclohexane $\left(\Phi_{\mathrm{f}}=0.52\right.$ and $\left.\Phi_{\mathrm{f}}+2 \Phi_{\mathrm{tc}}=0.98\right)$ and acetonitrile $\left(\Phi_{\mathrm{f}}=0.37\right.$, $\left.\Phi_{\mathrm{f}}+2 \Phi_{\mathrm{tc}}=1.01\right)($ Table 3$)$. This conclusion is corroborated by comparing with the TICT-forming p1CN and CNDPA and the TICT-inhibited ring-bridged model compounds $\mathbf{m 3 C N}$, p3CN, and CNDPAB. For example, compared to $\mathbf{m 1 C N}$, the smaller $\pi$-system CNDPA displays a fluorescence maximum at longer wavelength in acetonitrile (489 vs $434 \mathrm{~nm}$ ) but at shorter wavelength in cyclohexane (363 vs $397 \mathrm{~nm}$ ) (Table 1). In addition, the excited-state dipole moment is significantly larger for CNDPA (15.1 D) vs $\mathbf{m 1 C N}$ (8.5 D) (Table 2). For comparison, the dipole moments for the PICT and TICT state of p1CN are 9.1 and $16.4 \mathrm{D}$, respectively. ${ }^{32}$ Moreover, unlike the dramatic differences in fluorescence properties between p1CN and p3CN and between CNDPA and CNDPAB in acetonitrile, the corresponding difference between $\mathbf{m 1 C N}$ and (a) PICT

(b) TICT

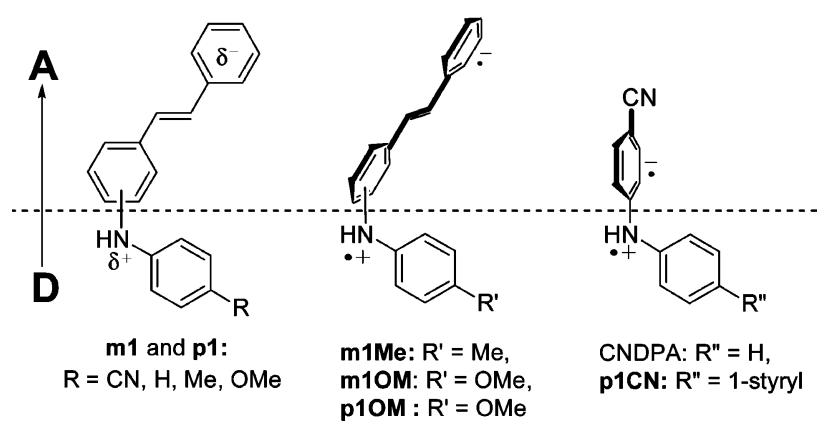

Figure 6. Schematic summary of the charge-transfer behavior of the PICT and TICT states of $\mathbf{m} \mathbf{1}$ and $\mathbf{p} \mathbf{1}$ and the TICT states of CNDPA in acetonitrile.

$\mathbf{m} 3 \mathbf{C N}$ is rather small, which can be simply attributed to the minor substituent effect.

In contrast to the different ICT behavior between the isomers $\mathbf{m 1 C N}$ and p1CN, TICT state formation for $\mathbf{m 1 O M}$ is as efficient as that for $\mathbf{p 1 O M} .^{32}$ This is manifested by the facts that the value of $\Phi_{\mathrm{f}}+2 \Phi_{\mathrm{tc}}$ substantially deviates from 1.0 in acetonitrile $(\sim 0.08)$ but not in cyclohexane $(0.98)$ and the $\Phi_{\mathrm{f}}$ value is significantly reduced on going from cyclohexane to acetonitrile (Table 3). Formation of a TICT state also accounts for the short-lived component in the decays of fluorescence upon detecting at the red edge of spectra (Table S1). The short lifetime (0.1 ns) for the TICT state indicates the presence of efficient nonradiative decay channels. On the basis of the behavior of $\Phi_{\mathrm{f}}+2 \Phi_{\mathrm{tc}} \approx 1.0$ and high $\Phi_{\mathrm{f}}$ values for the ring-bridged derivative $\mathbf{m 2 O M}$ in both acetonitrile and dichloromethane (Table 3), torsion of the stilbenyl-anilino $\mathrm{C}-\mathrm{N}$ bond in $\mathbf{m 1 O M}$ should be responsible for the TICT-forming process, as is the case of p1OM. The absence of well-resolved dual fluorescence for $\mathbf{m 1 O M}$ (Figure 3 ) in polar solvents also resembles the case of $\mathbf{p 1 O M}$ and can be attributed to the weak fluorescence of the TICT states.

A value of $\Phi_{\mathrm{f}}+2 \Phi_{\mathrm{tc}}=0.58$ for $\mathbf{m 1 M e}$ in acetonitrile also suggests the participation of a TICT state in the excited decay. As indicated by the absence of steady-state dual fluorescence and the short TICT lifetime $(0.05 \mathrm{~ns})$, the nonradiative decay processes for the TICT state should be very efficient. The TICT state also results from the twisting of the stilbenyl-anilino $\mathrm{C}-\mathrm{N}$ bond, as evidenced by the ring-bridged derivative m2Me. However, the efficiency of TICT formation is much lower for m1Me vs $\mathbf{m 1 O M}$ and becomes negligible in less polar solvents such as dichloromethane. This can be attributed to the weaker 4-methylanilino vs 4-methoxyanilino donor group. Nonetheless, formation of a TICT state for $\mathbf{m 1 M e}$ in acetonitrile is still in marked contrast to the para isomer p1Me, which is TICT free under the same condition.

Since the anilino donor in $\mathbf{m 1 H}$ is even weaker than the 4-methylanilino group in $\mathbf{m 1 M e}$ it is not unexpected to conclude that $\mathbf{m} 1 \mathbf{H}$ is TICT free in both dichloromethane and acetonitrile on the basis of $\Phi_{\mathrm{f}}+2 \Phi_{\mathrm{tc}} \approx 1.0$ in all investigated solvents (Table 3). The para isomer $\mathbf{p 1 H}$ was also shown to be free of TICT state formation under the same condition. A summary of the ICT behavior of both $\mathbf{m} \mathbf{1}$ and $\mathbf{p} \mathbf{1}$ in acetonitrile is depicted in Figure 6.

Energy Diagram. The distinct TICT-forming propensity in m1CN vs p1CN and in m1Me vs p1Me explicitly shows that the $\mathrm{D}-\mathrm{A}$ torsional motion depends not only on the relative 


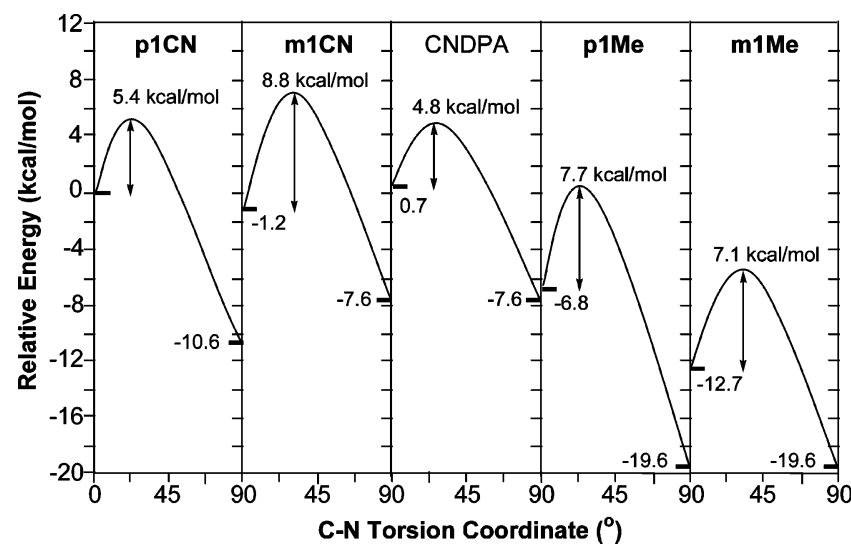

Figure 7. Potential-energy diagram for PICT $\rightarrow$ TICT through $\mathrm{C}-\mathrm{N}$ bond torsion for p1CN, m1CN, CNDPA, p1Me, and m1Me in acetonitrile. Energies are relative to PICT of $\mathbf{p 1 C N}$. Torsional barriers are derived from the Arrhenius equation at a preexponential factor of $10^{13}$.

strength of the $\mathrm{D}$ and $\mathrm{A}$ groups but also on the structural nature of the D-A constitution. To elucidate the origin of the meta vs para effects on the torsional motion reaction in aminostilbenes $1 \mathrm{CN}$ and $1 \mathrm{Me}$ one needs to compare the relative energies of the related states for both isomers: namely, to construct the state energy diagrams. However, to obtain the real quantitative energy diagram of different states for a specific compound is essentially impossible regarding the facts that (1) the exact structures of the PICT and TICT states are unknown and (2) as reflected by the broad fluorescence spectra there should exist a broad distribution of substrate/solvent structures and thus the state energies in each state. Nonetheless, under reasonable assumptions it might be possible to construct a relative and qualitative energy diagram for the purpose of comparison of the meta and para isomers. Since the differences between p1Me and $\mathbf{m 1 M e}$ are more significant in acetonitrile and acetonitrile has been the most common solvent for discussing the TICT behavior of arylamines, the following analysis and discussion will based on the data in acetonitrile. First, we assume that the 0,0 transition energy $\left(\lambda_{0,0}\right)$ corresponds to the transition from the optimized ground state to the Franck-Condon (FC) excited state. In addition, the PICT and TICT fluorescence maxima ( $\lambda_{\mathrm{f}, \mathrm{PICT}}$ and $\left.\lambda_{\mathrm{f}, \mathrm{TICT}}\right)$ were assumed to correspond to the averaged transition energies from the PICT and TICT states to their FC ground states, respectively. When the TICT fluorescence band is not resolved from the PICT band (e.g., p1Me and p1OM) or when the TICT state is not even formed (e.g., m1CN), other treatments would be made (see Supporting Information). Second, the relative energies of the optimized ground state and the FC ground states of PICT and TICT were evaluated by DFT calculations (Figure S5) ${ }^{37}$ The FC ground states of TICT were assumed to have a perpendicular geometry between the D (anilino or stilbenylamino group) and the A (benzonitrilo or stilbenyl group), where the D and the A groups are in a planar form. For the FC ground states of PICT it was assumed that the amino nitrogen is coplanar with the stilbenyl group and the rest part of the structure was optimized.

While the detailed energy diagrams about the optimized, PICT, and TICT states in $\mathrm{S}_{0}$ and $\mathrm{S}_{1}$ for CNDPA and the meta and para isomers of $\mathbf{1 C N}$ and $\mathbf{1 M e}$ in acetonitrile are provided as Supporting Information (Figures S6 and S7), Figure 7 shows the relative energies of their PICT and TICT states. It is interesting to note that the TICT states are at lower energies than the corresponding PICT states in all five cases, but only three of them (i.e., p1CN, CNDPA, and $\mathbf{m 1 C N}$ ) display significant TICT state formation. In particular, the driving force for the TICT state formation for $\mathbf{m 1 C N}$ is similar to that for CNDPA (>6.4 vs $8.3 \mathrm{kcal} / \mathrm{mol}$ ), but the outcome is entirely different: namely, one is negligible but the other is almost complete. Furthermore, p1Me has a larger driving force for TICT state formation than $\mathbf{m} \mathbf{1 M e}$, but the propensity of TICT state formation is in the opposite trend. Evidently, the torsional motion toward the TICT state for $\mathbf{m 1 C N}$ and p1Me must be too slow to compete with fluorescence and the nonradiative isomerization process. Since the rate constants for fluorescence and isomerization for $\mathbf{m 1 C N}$ in acetonitrile are $2.6 \times 10^{7}$ and $4.5 \times 10^{7} \mathrm{~s}^{-1}$, respectively (Table 3 ), the rate constant for the single-bond torsion $\left(k_{\mathrm{TICT}}\right)$ would be at least 1 order of magnitude lower than that for fluorescence (i.e., $k_{\text {TICT }}<3 \times$ $10^{6} \mathrm{~s}^{-1}$ ). Assuming that the preexponential factor for the singlebond torsion is in the order of $10^{13}$ at room temperature (23 ${ }^{\circ} \mathrm{C}$ ), the resulting torsional barrier would be $8.8 \mathrm{kcal} / \mathrm{mol}$. Likewise, the rate constants for fluorescence and isomerization for p1Me in acetonitrile are $2.3 \times 10^{8}$ and $3.4 \times 10^{8} \mathrm{~s}^{-1}$, respectively, the rate constant for the torsional motion should be at least 1 order of magnitude lower (i.e., $k_{\text {TICT }}<2 \times 10^{7}$ $\mathrm{s}^{-1}$ ). With the assumption of a preexponential factor of $10^{13}$ for the single-bond torsion, the resulting torsional barrier would be $7.7 \mathrm{kcal} / \mathrm{mol}$. For comparison, the $k_{\text {TICT }}$ values for $\mathbf{p 1 C N}$ and $\mathbf{m} 1 \mathrm{Me}$ are $\sim 1 \times 10^{9} \mathrm{~s}^{-1}\left(\Phi_{\mathrm{TICT}}=1-\Phi_{\mathrm{f}}-2 \Phi_{\mathrm{tc}} \approx 0.9\right)$ and $\sim 6 \times 10^{7} \mathrm{~s}^{-1}\left(\Phi_{\mathrm{TICT}}=1-\Phi_{\mathrm{f}}-2 \Phi_{\mathrm{tc}} \approx 0.42\right)$, respectively, corresponding to a barrier of $\sim 5.4$ and $\sim 7.1 \mathrm{kcal} /$ mol at a preexponential factor of $10^{13}$. In the case of CNDPA, the $k_{\text {TICT }}$ value should be at least 1 order of magnitude larger than the $k_{\mathrm{f}}$ value of its PICT state in order to account for the absence of PICT fluorescence (Figure 4). On the basis of the $k_{\mathrm{f}}$ value for CNDPAB in acetonitrile (Table 3 ), a value of $k_{\text {TICT }}$ $>3 \times 10^{9} \mathrm{~s}^{-1}$ and thus a torsional barrier of $<4.8 \mathrm{kcal} / \mathrm{mol}$ is predicted for CNDPA. These relative torsional barriers are also shown in Figure 7. It is interesting to note that the difference in the torsional barrier between m1Me and p1Me $(\mathbf{m 1 M e}<$ p1Me) is much smaller than that between m1CN and p1CN $(\mathbf{m} 1 \mathrm{CN} \gg \mathbf{p 1 C N})$.

Origin of the Torsional Barrier. Although kinetic controlled reactions are well known in thermal organic reactions, the conclusion of a kinetic but not thermodynamic inhibition of TICT state formation (i.e., $\mathbf{m 1 C N}$ and $\mathbf{p 1 M e}$ ) is unprecedented and deserves further discussion. As presented in the following, the differences in the propensity of TICT formation for the meta vs para isomers of $\mathbf{1 C N}$ and $\mathbf{1 M e}$ can be both attributed to their differences in charge-delocalization interactions in the precursor PICT states, which are weaker for the meta isomers.

To understand the negligible TICT formation for $\mathbf{m} 1 \mathbf{C N}$ it should be reminded that there is an inherent difference in the charge-transfer direction between the PICT and TICT states of $\mathbf{1 C N}$ (Figure 6). In analogy to the cases of p1CN and CNDPA, the TICT state for $\mathbf{m 1 C N}$ should also result from the twisting of the stilbenylamino (D)-benznitrilo (A) $\mathrm{C}-\mathrm{N}$ bond. This is in marked contrast to the PICT state, where charge transfer is from the anilino (D) to the stilbenyl (A) group. Thus, to initiate the single-bond torsional motion from the PICT state, the charge must be translocated from one end of the molecule to the other in order to induce changes in both the nuclear coordinate and 


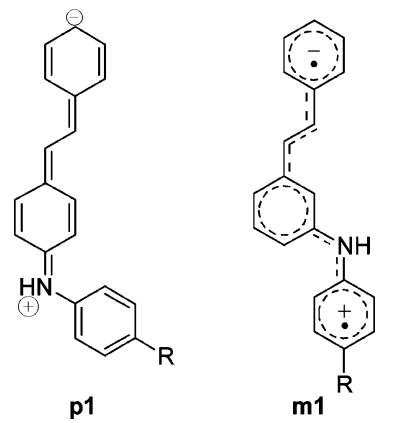

Figure 8. Schematic representation of the resonance-induced quinoidal character of $\mathbf{p} \mathbf{1}$ and the radical ion-pair character of $\mathbf{m} \mathbf{1}$ in the PICT states.

the reorientation of the solvent dipoles. While charge delocalization is expected to be feasible in p1CN due to the $p$-Ph bridge, it is blocked to a significant extent by the $m-\mathrm{Ph}$ bridge in $\mathbf{m 1 C N}$, as indicated by the slow charge-recombination process and the localized LUMO (Figure 5). In conjunction with the smaller thermodynamic driving force for $\mathbf{m} 1 \mathbf{C N}$ vs $\mathbf{p} \mathbf{1 C N}$, the barrier for the torsion toward TICT is expected to be much higher for $\mathbf{m 1 C N}$ vs $\mathbf{p} \mathbf{1 C N}$, which accounts for their distinct propensity for TICT state formation.

The situation is different in p1Me and m1Me because the charge-transfer direction for their PICT and TICT states is the same and, unlike the case of $\mathbf{p 1 C N}$, the TICT state results from the twisting of the stilbenyl (A) - anilino (D) $\mathrm{C}-\mathrm{N}$ bond (Figure $6 \mathrm{~b})$. Since the single-bond torsion has the same starting point as the double-bond torsion in $\mathbf{p 1 M e}$, the much more efficient double- vs single-bond torsion in p1Me explicitly indicates that its PICT state possesses a strong quinoidal character. This is consistent with the resonance-derived picture for the PICT state (Figure 8), which have been successfully applied for understanding the efficiency of trans - cis photoisomerization of trans4-aminostilbenes. ${ }^{29,30}$ The large double-bond character for the stilbenyl-anilino $\mathrm{C}-\mathrm{N}$ bond would lead to a large torsional barrier. Since the resonance is blocked by the $m$-Ph bridge in m1Me, the PICT state might be better described as an electron transfer from the anilino (D) to the stilbenyl (A) group (i.e., a radical ion-pair character) (Figure 8 ). This in turn suggests a less double-bond character for the stilbenyl-anilino $\mathrm{C}-\mathrm{N}$ bond and thus a lower barrier for its torsion. Indeed, this picture is consistent with the argument of less planar PICT states for $\mathbf{m} \mathbf{1}$ vs $\mathbf{p} 1$ on the basis of the less structured fluorescence spectra in nonpolar solvents. Nonetheless, the discussion in the Energy Diagram section has suggested that the $\mathrm{D}-\mathrm{A}$ torsional barrier for $\mathbf{p 1 M e}$ vs $\mathbf{m 1 M e}$ is not necessarily much higher. This might be in part attributed to the larger thermodynamic driving force for p1Me, which would lower the barrier to some extent. In addition to the torsional barrier, another important factor that accounts for the absence of TICT formation for p1Me is its large fluorescence and photoisomerization decay rates (Table 3 ), which further reduces the competition of the TICT-forming process.

The origin of negligible TICT formation for p1Me might also be responsible for the case of DCS, which shows no TICT behavior but appears to have a low-lying TICT state resulting from the twisting of the styryl-anilino $\mathrm{C}_{\mathrm{st}}-\mathrm{C}_{\mathrm{an}}$ bond. ${ }^{20}$ In other words, the PICT state of DCS possesses a quinoidal structure with the $\mathrm{C}_{\mathrm{st}}-\mathrm{C}_{\mathrm{an}}$ bond of a large double-bond character, resembling the case of p1Me (Figure 8). Indeed, the quinoidal picture for DCS is consistent with its large rates of isomerization and fluorescence $\left(2.5-16.7 \times 10^{8} \mathrm{~s}^{-1}\right)$ in acetonitrile. ${ }^{21}$

Our results could also provide insights into the distinct TICTforming propensity between $3 \mathrm{DMABN}$ and $\mathrm{DMABN}$. Both the experimental (e.g., solvatofluorochromism) ${ }^{18}$ and theoretical studies ${ }^{19}$ have indicated that the LE state of 3DMABN possesses a larger charge-transfer character (i.e., mixed ${ }^{1} \mathrm{~L}_{\mathrm{a}} /{ }^{1} \mathrm{~L}_{\mathrm{b}}$ character) than that of DMABN $\left({ }^{1} \mathrm{~L}_{\mathrm{b}}\right)$. This in turns might suggest that the LE state of 3DMABN is of some quinoidal character, and thus, the benznitrilo-dimethylamino $\mathrm{C}-\mathrm{N}$ bond possesses some double-bond character. This is different from the case of DMABN, the LE state of which has recently been suggested to be of antiquinoidality. ${ }^{24}$ Furthermore, like the case of $\mathbf{m 1 M e}$ vs $\mathbf{p} 1 \mathrm{Me}$, the LE state of 3DMABN is lower in energy by $\sim 10$ $\mathrm{kcal} / \mathrm{mol}$ than that for DMABN, ${ }^{14}$ corresponding to a smaller thermodynamic driving force toward the TICT state.

While all the above discussion about the mechanism of TICT formation conforms to the adiabatic precursor (PICT) - successor (TICT) model, a nonadiabatic reaction mechanism has recently been shown to play an important role in accounting for the TICT formation in DMABN. ${ }^{26,27}$ The latter mechanism suggests that the TICT state is directly formed from the FC structure on $\mathrm{S}_{2}$ through a conical intersection, corresponding to a nearly barrierless TICT-forming pathway. In this context, the absence of TICT formation for 3DMABN might suggest that the nonadiabatic route is either rather inefficient or significantly distorted toward the LE state because of the lower LE state and the higher torsional barrier toward the TICT state. Such a nonadiabatic route appears to be unimportant for trans-aminostilbenes in view of the different electronic structures from the DMABN systems: namely, the polar PICT state is the $\mathrm{S}_{1}$ state rather than the $S_{2}$ state in aminostilbenes.

\section{Concluding Remarks}

The most important finding in this work is that the presence of a low-lying TICT state for a D-A system is insufficient to argue for its formation because the rate of the torsional motion could be too slow to compete with the other deactivation channels. The evidence relies on the distinct TICT-forming propensity between the meta and the para isomers of transaminostilbenes $\mathbf{1 C N}$ and $\mathbf{1 M e}$. According to their energy diagrams, the PICT $\rightarrow$ TICT process is exothermic for all four cases, and the thermodynamic driving force is larger for the para isomers (i.e., p1CN $>$ m1CN and p1Me $>$ m1Me). However, only two of them are TICT forming (i.e., p1CN and $\mathbf{m 1 M e}$ ), indicating that the torsional processes in the other two isomers (i.e., $\mathbf{m 1 C N}$ and $\mathbf{p 1 M e}$ ) are much slower than the decay processes of fluorescence and photoisomerization. For aminostilbenes $1 \mathbf{C N}$, the TICT state has an opposite charge-transfer direction from the PICT state, and thus, facile charge redistribution is required for initiating the changes in nuclear coordinate and the reorientation of the solvent dipoles. The poor chargeredistribution ability through the $m$-Ph bridge in $\mathbf{m 1 C N}$ accounts for the slow TICT-forming process. On the other hand, the charge-transfer direction is the same for the PICT and TICT states of 1Me, and thus, the TICT-forming propensity mainly depends on the bonding character of the PICT state. The strong resonance-induced quinoidal character in the PICT state of p1Me disfavors the torsion of the stilbenyl - anilino $\mathrm{C}-\mathrm{N}$ bond toward TICT but favors the torsion of the $\mathrm{C}=\mathrm{C}$ bond for 
photoisomerization. In addition, the $p$ - $\mathrm{Ph}$ linker allows fast charge recombination in the PICT state, which facilitates the fluorescence decay. Although the driving force toward the TICT state is smaller for m1Me vs p1Me, the meta conjugation in m1Me results in a weaker quinoidal character and a slower charge-recombination process in its PICT state, making the single-bond torsion a competitive decay process. A slow reaction rate could also interpret the negligible TICT formation for aminostilbene DCS and aminobenzonitrile 3DMABN. Our results have provided insights not only into the kinetic aspects of the TICT model but also into the meta vs para conjugation effects on the nature of ICT states. Since the phenomenon of meta vs para isomer-dependent photochemical reactions (e.g., solvolysis, ${ }^{38}$ trans - cis photoisomerization, ${ }^{39}$ and excited-state proton transfer ${ }^{40}$ ) is often termed the "meta effect", ${ }^{41}$ our results also reveal a new type of meta effect in the photochemistry.

\section{Experimental Section}

Materials. Solvents for spectra and quantum yield measurements were HPLC grade and used as received. THF was dried by sodium metal and distilled before use. All other solvents for spectra and quantum yield measurements were HPLC grade and used as received. Aminostilbenes $\mathbf{m} \mathbf{1}$ and diarylamines CNDPAs were prepared by palladium-catalyzed amination reactions ${ }^{42}$ between trans-3-bromostilbene or 4-bromobenzonitrile and the corresponding commercially available arylamines. ${ }^{30}$ The synthesis of ring-bridged compounds m2Me, m2OM, m3CN, and CNDPAB also followed the same strategies previously reported for the para isomers. ${ }^{30-32}$ All new compounds were identified by ${ }^{1} \mathrm{H}$ NMR, ${ }^{13} \mathrm{C}$ NMR, MS, IR, and/or elemental analysis. The reaction schemes and characterization data are provided as Supporting Information.

Methods. Electronic spectra were recorded at room temperature (23 $\left.\pm 1{ }^{\circ} \mathrm{C}\right)$. UV-visible spectra were measured on a Cary300 doublebeam spectrophotometer. Fluorescence spectra were recorded on a PTI QuantaMaster C-60 spectrometer and corrected for the response of the

(38) Dichiarante, V.; Dondi, D.; Protti, S.; Fagnoni, M.; Albini, A. J. Am. Chem. Soc. 2007, 129, 5605-5611 and references cited therein.

(39) Lewis, F. D.; Yang, J.-S. J. Am. Chem. Soc. 1997, 119, 3834-3835.

(40) (a) Lewis, F. D.; Crompton, E. M. J. Am. Chem. Soc. 2003, 125, 40444045. (b) Crompton, E. M.; Lewis, F. D. Photochem. Photobiol. Sci. 2004, 3, 660-668.

(41) (a) Zimmerman, H. E. J. Am. Chem. Soc. 1995, 117, 8988-8991. (b) Zimmerman, H. E. J. Phys. Chem. A 1998, 102, 5616-5621.

(42) Old, D. W.; Harris, M. C.; Buchwald, S. L. Org. Lett. 2000, 2, $1403-$ 1406. detector. The optical density (OD) of all solutions was about 0.1 at the wavelength of excitation. A $\mathrm{N}_{2}$-bubbled solution of phenanthrene $\left(\Phi_{\mathrm{f}}\right.$ $=0.13$ in cyclohexane $)^{43}$ was used as a standard for the fluorescence quantum yield determinations of compounds under $\mathrm{N}_{2}$-bubbled solutions with solvent refractive index correction. An error of $10 \%$ is estimated for the fluorescence quantum yields. Fluorescence decays were also measured at room temperature by the Edinburgh FLS920 spectrometer with a gated hydrogen arc lamp using a scatter solution to profile the instrument response function. The goodness of the nonlinear leastsquares fit was judged by the reduced $\chi^{2}$ value $(<1.2$ in all cases), randomness of the residuals, and autocorrelation function. Quantum yields of photoisomerization were measured on optically dense $\mathrm{N}_{2^{-}}$ bubbled solutions $\left(10^{-3} \mathrm{M}\right)$ at $313 \mathrm{~nm}$ using a $75-\mathrm{W}$ Xe arc lamp and monochromator. trans-Stilbene was used as a reference standard $\left(\Phi_{\mathrm{tc}}=0.50\right.$ in hexane $) .^{44}$ The extent of photoisomerization $(<10 \%)$ was determined using HPLC analysis (Waters 600 Controller and 996 photodiode array detector, Thermo APS-2 Hypersil, heptane and ethyl acetate mixed solvent) without back-reaction corrections. The reproducibility error was $<10 \%$ of the average. AM1 and DFT calculations were performed on a PC cluster using the algorithms supplied with the package of Gaussian 03 Revision B.02, a product of Gaussian Inc. ${ }^{45}$

Acknowledgment. We thank the National Science Council of Taiwan for financial support, the National Center for Highperformance Computing of Taiwan for facilities, and Prof. Tsai, H.-H. G. (NCU) for helpful discussion.

Supporting Information Available: Detailed synthetic schemes and characterization data for new compounds, dual fluorescence decay times for $\mathbf{m 1 M e}$ and $\mathbf{m 1 O M}$, solvatofluorochromic plots for $\mathbf{m} 1-\mathbf{m} 3$ and CNDPAs, absorption and fluorescence spectra for $\mathbf{m} 2 \mathrm{Me}, \mathbf{m} \mathbf{2 O M}$, and $\mathbf{m 3 C N}$, DFT-optimized ground-state structures and energies for the meta and para isomers of $1 \mathbf{C N}$ and $1 \mathrm{Me}$, detailed accounts of the energy diagrams for CNDPA, $\mathbf{1 C N}$ and 1Me, and complete ref 45 (PDF). This material is available free of charge via the Internet at http://pubs.acs.org.

\section{JA0741022}

(43) Berlman, I. B. Handbook of Fluorecence Spectra of Aromatic Molecules, 2nd ed.; Academic Press: New York, 1971.

(44) Malkin, S.; Fischer, E. J. Phys. Chem. 1964, 68, 1153-1163.

(45) Frisch, M. J. et al. Gaussian 03, revision B.03; Gausian, Inc.; Pittsburgh, PA, 2003; full reference given in the Supporting Information. 